\title{
Comunicação
}

[Communication]

\section{Resistência a antimicrobianos de Escherichia coli isolada de dejetos suínos em esterqueiras}

\author{
[Antibiotic-resistance of Escherichia coli isolates from stored pig slurry] \\ F.F.P. Silva ${ }^{1}$, M.A.A. Santos ${ }^{2}$, V. Schmidt ${ }^{1^{*}}$ \\ ${ }^{1}$ Faculdade de Veterinária - UFRGS \\ Av. Bento Gonçalves, 9090. \\ 91509-900 - Porto Alegre, RS \\ ${ }^{2}$ Centro de Ciências Agrárias - UFSC - Florianópolis, SC
}

\begin{abstract}
A intensificação dos métodos de produção em suinocultura levou ao aparecimento de uma série de doenças relacionadas à introdução das novas tecnologias. Para o controle dessas enfermidades, assumiram papel preponderante os produtos antimicrobianos, usados principalmente na ração. A função desses produtos tem sido restabelecer o equilíbrio perdido, criando as condições necessárias para uma suinocultura lucrativa (Sobestiansky e Barcellos, 1998). O uso crescente de antimicrobianos em animais tem sido apontado como uma das possíveis causas da emergência de linhagens bacterianas resistentes (Costa et al., 2006; Macedo et al., 2007). Nesse sentido, o monitoramento do nível de resistência de bactérias intestinais, como Escherichia coli, tem sido proposto como um bom indicador da pressão de seleção exercida pelos antimicrobianos (Bogaard e Stobbering, 1999).
\end{abstract}

Outra preocupação, relacionada ao processo de produção intensiva de suínos, tem sido a quantidade de dejetos gerados nas granjas, bem como o potencial poluente e a carga bacteriana que esses representam. Como forma de atenuar o impacto que os dejetos representam ao ambiente é imprescindível que as granjas de suínos possuam sistemas de tratamento de dejetos (Strauch, 1991).

A eficácia do sistema de lagoas interligadas para o tratamento de dejetos suínos (Schmidt et al., 2002a) bem como o papel que esse sistema exerce sobre a multirresistência a antimicrobianos (Schmidt et al., 2002b) já foram anteriormente demonstrados. Entretanto, a implantação e manutenção de um sistema de lagoas interligadas requerem investimentos significativos, normalmente acima da capacidade do produtor. Dessa forma, as unidades de produção, quer sejam integradas a uma empresa ou independentes, ainda permanecem utilizando sistemas de tratamento de dejetos simplificados (esterqueiras). Esses sistemas, construídos para armazenar os dejetos antes de aplicá-lo ao solo, estão integrados à prática agrícola e apresentam custo de implantação e operação inferior aos demais sistemas (Belli Filho et al., 2001). Apesar de o esterco suíno ser um fertilizante, seu uso inadequado pode comprometer a qualidade do solo e da água (Ceretta et al., 2003).

A fim de determinar o perfil de resistência a antimicrobianos de amostras de E. coli, oito sistemas de armazenamento de dejetos suínos foram monitorados nos estados do Rio Grande do Sul e de Santa Catarina. Os dejetos liquefeitos são colocados em esterqueiras (Maroso et al., 2003) e nelas permanecem armazenados por um período mínimo de 120 dias. A primeira amostra de dejetos foi coletada, em cada uma das propriedades, na canaleta dos galpões de suínos caracterizando-se como o "momento zero" de armazenagem. As demais amostras foram coletadas, sempre do lado oposto à entrada dos dejetos na esterqueira a uma profundidade

Recebido em 9 de outubro de 2007

Aceito em 27 de abril de 2008

*Autor para correspondência (corresponding author)

E-mail: veronica.schmidt@ufrgs.br; 
mínima de $50 \mathrm{~cm}$ e igual distância das bordas, após 30, 60, 90 e 120 dias do "momento zero". Nas amostras coletadas foi realizada a pesquisa do número mais provável (NMP) de coliformes totais $(\mathrm{CT})$ e termotolerantes $(\mathrm{CF})$, por meio da técnica dos tubos múltiplos. Em seguida, amostras de $E$. coli foram obtidas em ágar McConckey (a partir dos tubos de caldo E.C. com formação de gás). Em cada placa com ágar McConkey, foram coletadas, aleatoriamente, três colônias com características de E. coli. As colônias foram identificadas por meio de provas bioquímicas, segundo Lennette et al. (1985). A seguir, as 96 amostras identificadas como E. coli foram armazenadas em caldo cérebro coração com $20 \%$ de glicerol a $-20^{\circ} \mathrm{C}$ até serem testadas quanto à resistência a antimicrobianos. Para realização do antibiograma, utilizou-se o método de difusão em ágar (Barry e Thornsberry, 1985), com discos (Cecon) impregnados com os seguintes antimicrobianos: ácido nalidíxico $(30 \mu \mathrm{g})$, amicacina $(30 \mu \mathrm{g})$, amoxacilina/ácido clavulânico $(20 / 10 \mu \mathrm{g})$, ampicilina $(10 \mu \mathrm{g})$, cefaclor $(30 \mu \mathrm{g}), \quad$ ciprofloxacina $(5 \mu \mathrm{g})$, cloranfenicol $(30 \mu \mathrm{g})$, estreptomicina $(10 \mu \mathrm{g})$, gentamicina $(10 \mu \mathrm{g})$, neomicina $(30 \mu \mathrm{g})$, sulfonamida $(300 \mu \mathrm{g})$, sulfa/trimetoprima $(5 \mu \mathrm{g})$; tetraciclina $(30 \mu \mathrm{g})$ e tobramicina $(10 \mu \mathrm{g})$.

Para o cálculo do índice de multirresistência acumulada (MAR) as amostras de E. coli foram dividas em dois grupos: unidade de produção de leitões (UPL) e granjas de ciclo completo ou terminação (CC). O índice MAR foi calculado separadamente para cada grupo nos diferentes períodos de armazenamento (zero a 120 dias), por meio da fórmula $\mathrm{a} /(\mathrm{bXc})$, onde a é o escore de resistência agregada de todas as amostras de $E$. coli pertencentes ao grupo no período; b é o número de antimicrobianos testados no estudo e c é o número de amostras de $E$. coli no grupo testado no mesmo período (Krumperman, 1983).

Apenas seis $(6,25 \%)$ amostras de E. coli isoladas foram sensíveis a todos os antimicrobianos testados. As demais foram resistentes a pelo menos um antimicrobiano sendo $36(37,5 \%)$, a pelo menos quatro destes. $O$ número de marcadores de resistência concomitantes variou entre um $(n=8)$ e oito $(n=5)$, e aproximadamente $47 \%$ das amostras a dois ou três antimicrobianos. O percentual de resistência foi: $82,3 \%$ à tetraciclina, $64 \%$ ao ácido nalidíxico, $41 \%$ à ampicilina, $36 \%$ à sulfa/trimetoprima, $34 \%$ à sulfonamida, $27 \%$ ao cloranfenicol, $19 \%$ à ciprofloxacina, $16 \%$ ao cefaclor, $7,3 \%$ à estreptomicina, $1 \%$ à neomicina, $1 \%$ à amoxacilina/ácido clavulânico e $1 \%$ à amicacina. Todas as amostras foram sensíveis a gentamicina e tobramicina.

Em abatedouros europeus também foi observada alta prevalência de E. coli resistente a antimicrobianos de uso na suinocultura (tetraciclina e sulfa/trimetoprima) bem como a aqueles de uso restrito na veterinária, como exemplo o cloranfenicol (Bogaard et al., 2000).

Foram observados, neste estudo, elevados níveis de resistência à tetraciclina, a sulfonamida e à sulfa/trimetropina. Resistência a esses antimicrobianos tem sido relatada em casos de diarréia causada por $E$. coli em leitões (Sobestiansky e Barcellos, 2001; Macedo et al., 2007) e amostras de E. coli isoladas de suínos e de ambiente (Costa et al., 2006). Concomitantemente, foi verificada alta resistência a antimicrobianos de uso mais recente, como é o caso das cefalosporinas e quinolonas. Segundo alguns estudos, isso ocorreria em virtude de vários genes de resistência estarem localizados em elementos transponíveis (Schwarz e Chaslus-Dancla, 2001).

A resistência à ciprofloxacina $(19 \%)$ e ao ácido nalidíxico (64\%) não tem sido associada à transferência gênica, mas à expressão de uma capacidade intrínseca da $E$. coli em desenvolver resistência quando exposta a um ambiente com pressão de seleção. Sendo que essa pressão pode ser exercida por qualquer uma das quinolonas ou fluoroquinolonas, o que resulta numa resistência a todo o grupo (Webber e Piddock, 2001). Em estudo anterior desenvolvido por Schmidt et al. (2002b), observou-se perfil de resistência a antimicrobianos de uso não corrente em animais, a qual pode ter sido desencadeada pela utilização de um antimicrobiano pertencente ao mesmo grupo. No presente estudo, comparando-se o percentual de amostras resistentes no dejeto retirado das canaletas (momento zero) e após 120 dias de armazenagem, foi observada uma tendência de aumento no número de amostras resistentes aos antimicrobianos: ampicilina, cefaclor, sulfa/trimetoprima, cloranfenicol, sulfonamida, tobramicina e estreptomicina, e de redução a amicacina, ciprofloxacina e tetraciclina. Uma grande variabilidade nos perfis de resistência apresentados também pôde ser verificada sendo que o mais freqüente (ap-na-s-ct) estava presente em $13(16,9 \%)$ amostras. 
Existem dados conflitantes a respeito do efeito que os sistemas de tratamento/armazenamento de dejetos exercem na resistência a antimicrobianos em bactérias. Embora nem os tratamentos aeróbios ou os anaeróbios pareçam exercer influência na resistência bacteriana aos antimicrobianos, Morozzi et al. (1988) observaram tendência ao aumento do percentual de amostras resistentes em sistemas aeróbios. Schmidt et al. (2002a), no entanto, verificaram tendência à menor resistência em amostras isoladas após a passagem pelas lagoas aeróbias. Neste estudo, sob condições de anaerobiose, verificou-se uma tendência ao aumento do número de amostras multirresistentes $(9 / 13)$ aos 120 dias de armazenagem quando comparado ao dejeto bruto (4/21). Este resultado poderia ser decorrente do tempo de retenção, uma vez que, para Bell et al. (1983), a seleção ou surgimento de amostras resistentes em certos sistemas ocorreria em tempo de retenção superior a 45 dias.

Segundo Krumperman (1983), amostras de $E$. coli com índice MAR superior a 0,2 poderiam agir como reservatórios de genes de resistência para outras bactérias, constituindo-se em risco inclusive à população humana. Assim, nas amostras provenientes de granjas de ciclo completo ou terminação (CC) determinou-se índice MAR de alto risco a partir dos 30 dias de armazenamento. Por outro lado, isso não foi verificado nas unidades de produção de leitões (UPL), onde o índice MAR manteve-se baixo durante todo o período de estudo, exceto na última coleta aos 120 dias de armazenamento (Tab. 1). Verificou-se resistência à tetraciclina $(100 \%)$ e ao ácido nalidíxico $(100 \%)$, indicando apenas dois marcadores de resistência, nas amostras provenientes da UPL e isoladas na canaleta (momento zero de armazenamento). Entretanto, aos 120 dias de armazenamento o número de marcadores de resistência variou de quatro a oito, observando-se resistência ao cefaclor $(100 \%)$, ao ácido nalidíxico $(100 \%)$, à sulfa/trimetroprima $(100 \%)$, à tetraciclina $(100 \%)$, à ampicilina $(80 \%)$, à sulfonamida
$(80 \%)$, ao cloranfenicol $(80 \%)$ e à ciprofloxacina $(60 \%)$.

Tabela 1. Índice de multirresistência acumulada de amostras de E. coli isoladas em esterqueiras de unidade de produção de leitões (UPL) e granjas de ciclo completo ou terminação (CC), de acordo com o tempo de armazenamento

\begin{tabular}{ccc}
\hline \multirow{2}{*}{$\begin{array}{c}\text { Tempo de } \\
\text { armazenamento } \\
\text { (dias) }\end{array}$} & \multicolumn{2}{c}{ Sistema de produção } \\
\cline { 2 - 3 } & UPL & CC \\
\hline zero & 0,143 & 0,194 \\
30 & 0,161 & 0,294 \\
60 & 0,071 & 0,228 \\
90 & 0,133 & 0,310 \\
120 & 0,486 & 0,222 \\
\hline
\end{tabular}

O uso freqüente de antimicrobianos leva a uma maior proporção de amostras de E. coli resistentes a antimicrobianos (Costa et al., 2006; Macedo et al., 2007), fato que explicaria o perfil de multirresistência encontrado nas granjas de ciclo completo ou terminação, uma vez que, o uso de antimicrobianos nas rações, especialmente na fase de creche, é uma prática corrente na moderna suinocultura intensiva (Fávero, 2003). $\mathrm{O}$ aumento no perfil de multirresistência observado aos 120 dias na UPL poderia estar associado à ocorrência de um surto de origem bacteriana e a medicação com antimicrobianos. Pois, a recuperação de suínos doentes depende da aplicação imediata de medidas profiláticas, especialmente isolamento e tratamento (Fávero, 2003).

Dessa forma, o monitoramento do perfil de resistência em amostras de E. coli do efluente poderá vir a ser necessário como um novo parâmetro de impacto ambiental a ser avaliado. Por outro lado, os níveis de multirresistência bacteriana só poderão ser efetivamente diminuídos por medidas que interfiram na administração de antimicrobianos aos animais.

Palavras-chave: Escherichia coli, resistência antimicrobiana, dejetos suínos, esterqueira

\begin{abstract}
The antimicrobial resistance of 96 Escherichia coli strains isolated from a stabilization pond system on a pig-breeding farm was evaluated. Strains were tested for their resistance against 14 antimicrobial using the agar diffusion method. E. coli strains showed resistance to tetracycline (82.3\%), nalidixic acid (64\%), ampicilin (41\%), sulfamethoxazole/trimethoprin (36\%), sulfonamide (34\%), cloranphenicol (274\%),
\end{abstract}


ciprofloxacin (19\%), cefaclor (16\%), streptomicyn (7.3\%), neomicyn (1\%), amoxacilin/ clavulanic acid (1\%), and amikacin (1\%). No resistance was observed to gentamicin and tobramycin, and 37.5\% of $\mathrm{E}$. coli strains were resistant to four or more antimicrobials. The multiresistance pattern was found in strains isolated during all sampled period. Strains showed a high variability in the antimicrobial resistance pattern.

Keywords: Escherichia coli, antimicrobial-resistance, pig slurry, stored waste

\section{AGRADECIMENTOS}

À FAPERGS pelo financiamento do presente projeto (ARD 03/0385.6).

\section{REFERÊNCIAS BIBLIOGRÁFICAS}

BARRY, A.L.; THORNSBERRY, C. Susceptibility test: diffusion test procedures. In: LENNETE, E.H.; BALOWS, A.; HAUSLER JR, W.J. et al. Manual of clinical microbiology, 4.ed. Washington: ASM, 1985. cap. 102, p.978-987.

BELL, J.B.; ELLIOT, G.E.; SMITH, D.W. Influence of sewage treatment and urbanization on selection of multiple resistance in fecal coliform populations. Appl. Environ. Microbiol., v.46, p.227-232, 1983.

BELLI FILHO, P.; CASTILHOS, A.B.; COSTA, R.H.R. et al. Tecnologias para o tratamento de dejetos suínos. Rev. Bras. Eng. Agric. Amb., v.5, p.166-170, 2001.

BOGAARD, A.E. van den; STOBBERING, E.E. Antibiotic usage in animal: impact on bacterial resistance and public healt. Drugs, v.58, p.589-607, 1999.

BOGAARD, A.E.J.M van den; LONDON, N.; STOBBERINGH, E. Antimicrobial resistance in pig faecal samples from the Netherlands (five abattoirs) and Sweden. J. Antimicrob. Chemother., v.45, p.663-671, 2000 .

CERETTA, C.A.; DURIGON, R.; BASSO, C.J. et al. Características químicas do solo sob aplicação de esterco líquido de suínos em pastagem natural. Pesq. Agropec. Bras., v.38, p.729-735, 2003.

COSTA, M.M.; SILVA, M.S.; SPRICIGO, D.A. et al. Caracterização epidemiológica, molecular e perfil de resistência aos antimicrobianos de Escherichia coli isoladas de criatórios suínos do sul do Brasil. Pesq. Vet. Bras., v.26, p.5-8, 2006.

FÁVERO, J.A. Produção de suínos: sistema de produção. v.1. Concórdia: Embrapa-CNPSA, 2003. Disponível em: $<$ http://www.cnpsa.embrapa.br/SP/suinos/index.html.> Acessado em: 11 jan. 2006.

KRUMPERMAN, P. H. Multiple antibiotic resistance indexing of Echerichia coli to identify high-risk sources of fecal contamination of foods. Appl. Environ. Microbiol., v.46, p.165-170, 1983.

LENNETTE, E.H.; BALLOWS, A.; HAUSLER, W.J. et al. Manual of clinical microbiology. 4.ed. Washington: ASM, 1985. 1149p.

MACÊDO, N.R.; MENEZES, C.P.L.; LAGE, A.P. et al. Detecção de cepas patogênicas pela PCR multiplex e avaliação da sensibilidade a antimicrobianos de Escherichia coli isoladas de leitões diarréicos. Arq. Bras. Med. Vet. Zootec., v.59, p.1117-1123, 2007.

MAROSO, M.T.D.; TORRES, C.A.; BOROWSKY, L.M. et al.. Caracterização de sistemas de tratamento de dejetos em unidades integradas de produção de suínos no município de Três Passos. In: MOSTRA DE INICIAÇÃO CIENTIFICA DA UPF, 13., 2003, Passo Fundo. Anais... Passo Fundo, 2003. p.88. (Resumo).

MOROZZI, G.; SPORTOLARI, R.; CALDINI, G. et al. The effect of anaerobic and aerobic wastewater treatment on faecal coliforms and antibiotic-resistant faecal coliforms. Zentralbl. Bakteriol. Mikrobiol. Hyg.[B], v.185, p.340-349, 1988.

SCHWARZ, S.; CHASLUS-DANCLA, E. Use of antimicrobials in veterinary medicine and mechanisms of resistance. Vet. Res., v.32, p.201-226, 2001.

SCHMIDT, V.; GOTTARDI, C.P.T.; SANTOS, M.A.A. et al. Perfil físico-químico e microbiológico de uma estação de tratamento de dejetos suínos. Ars Vet., v.18, p.1-12, 2002a.

SCHMIDT, V.; GOTTARDI, C.P.T.; CARDOSO, M.R.I. Resistência a antimicrobianos de amostras de Escherichia coli isoladas em estação de tratamento de dejetos de suínos. In: CONGRESSO LATINO AMERICANO DE SUINICULTURA, 1., 2002, Foz do Iguaçu. Anais... Concórdia, 2002b. p.27-28.

SOBESTIANSKY, J.; BARCELLOS, F. (Eds). Clínica veterinária em sistemas intensivos de produção de suínos e relatos de casos clínicos. Goiás:[s.n.], 2001. 1543p.

STRAUCH, D. Survival of pathogenic micro-organisms and parasites in excreta, manure and sewage sludge. Vet. Sci. Tech., v.10, p.813-846, 1991.

WEBBER, M.; PIDDOCK, L.J.V. Quinolone resistance in Escherichia coli. Vet. Res., v.32, p.275-284, 2001. 